\title{
Pitfalls in the quantitative imaging of glutathione in living cells
}

\author{
Cristina Cossetti ${ }^{1}$, Gianna Di Giovamberardino ${ }^{2}$, Rossella Rota (i) ${ }^{1}$ \& Anna Pastore (iD ${ }^{2}$
}

Biothiols have crucial roles in maintaining redox homeostasis in biological systems. Glutathione (GSH) and its precursor, cysteine (Cys), are the two most abundant low-molecular weight thiols in living cells, and their intracellular abnormal levels are associated with diseases ${ }^{1}$. GSH is a ubiquitous thiol-containing tripeptide, which has a central role in cell biology. It is implicated in the cellular defense against xenobiotics and naturally occurring deleterious compounds, such as free radicals and hydroperoxides $^{2}$. The ratio of GSH to its oxidized form (glutathione disulfide, GSSG) is an indicator of the redox state of the cell, and the alteration of this ratio can lead to a number of human pathologies ${ }^{3}$. Consequently, the assessment of abnormal levels of thiol-containing substances in biological systems may provide valuable information for the early diagnosis of some diseases ${ }^{2,3}$.

Recently, Jiang et al. $^{4}$ reported the characterization of a fluorescent probe for quantitative real-time imaging of GSH in living cells. This probe is commercially available as RealThiol (RT, to be used for calibrations) and RealThiol AM Ester (RT-AM, to be used with cells) GSH Detection Probe (Kerafast, Boston, MA, USA). Authors performed an impressive number of experiments, aimed to demonstrate that RT preferentially reacts with GSH under physiological conditions. In contrast to that reported by Jiang et al. ${ }^{4}$, we show here that $\mathrm{RT}$ is able to react with both GSH and Cys (Fig. 1a, b).

It should be noted that analytical methods for thiols assessment typically involve separation steps, and one of the most used method for the separation of biothiols is high performance liquid chromatography (HPLC) coupled either with fluorescence ${ }^{5}$ (HPLC-FD), mass-spectrometry ${ }^{6}$ (HPLC-MS), or tandem massspectrometry detection $^{7}$ (HPLC-MSMS). Although Jiang et al. ${ }^{4}$ used HPLC-MS for some of the GSH measurements, they do not show whether Cys is present or not in their HeLa cells before and after treatments with $\mathrm{H}_{2} \mathrm{O}_{2}$. In addition, they quantify thiols by HPLC-MS after reaction with $N$-methylmaleimide (NMM), using $100 \mu \mathrm{M}$ NMM in some experiments, and $1 \mathrm{mM}$ NMM in others. $\mathrm{NMM}$ is identical to the other chemical used for -SH groups alkylation, $\mathrm{N}$-ethylmaleimide (NEM). Although NEM reacts with thiols by a very fast Michael addition reaction at neutral or slightly acidic $\mathrm{pH}$, this reaction is reversible, and an excess of
NEM should be used to avoid the possible migration of the maleimide group among different thiols ${ }^{3}$. This is not accomplished by Jiang et al. ${ }^{4}$, that use $100 \mu \mathrm{M}$ or $1 \mathrm{mM}$ NMM. These concentrations are insufficient to be sure that all thiols present are blocked, especially in cells where GSH levels are higher than $1 \mathrm{mM}[3]$.

Over the years, great efforts have been devoted to develop reaction-based fluorescent sensors for the detection of thiols in living systems ${ }^{8}$. Nonetheless, Yin et al. ${ }^{8}$ just highlight that despite a large number of thiol-reactive reagents and probes have been commercially available for many years, filling an entire chapter of the Molecular Probes Handbook ${ }^{9}$, most of them are nonselective, forming covalent adducts with any sulfhydrylcontaining molecules. Notably, it is important to realize that such universal thiol-reactive probes are sometimes marketed or reported in the literature as GSH (or Cys) selective. This erroneous interpretation is often based on the assumption that GSH is believed to be the most abundant thiol in cells, and any probe signaling from an interaction with Cys or other thiols would be negligible. This may be true, but it has been clearly demonstrated that their concentrations varies not only depending on the cell type and treatments, but also during cell proliferation in comparison with quiescent or not dividing cells ${ }^{10}$. Indeed, in our more that ten-year experience on thiols measurements in various cells and tissues $^{11-15}$, the concentration of GSH has been often well below $1 \mathrm{mM}$, and comparable to that of Cys (Fig. 1c). This is also true in $\mathrm{H}_{2} \mathrm{O}_{2}$-treated HeLa cells, where GSH and Cys levels become almost identical after treatment (Fig. 1d).

On the basis of the literature reports and on our data, we believe that an unaware probe end-user could encounter artificially attributed high values of GSH that are arising instead from both GSH and Cys, including Cys-protein residues. Because of the possible presence of high Cys levels, the use of RT probe for GSH quantification must be applied cautiously. The reactivity of RT probe towards GSH is obviously not questioned, and the use of this probe could be useful after verifying, possibly by HPLC, that in an experimental system the amount of GSH is at least one order of magnitude greater than that of Cys, both before and after any treatment aimed to change thiols levels.

\footnotetext{
${ }^{1}$ Laboratory of Epigenetics of Pediatric Sarcomas, Division of Hematology/Oncology, Children's Hospital and Research Institute "Bambino Gesù", Viale di San Paolo 15, Rome 00146, Italy. ${ }^{2}$ Laboratory of Molecular Genetics and Functional Genomics, Division of Genetic and Rare Disease, Children's Hospital and Research Institute "Bambino Gesù", Viale di San Paolo 15, Rome 00146, Italy. These authors contributed equally: Rossella Rota, Anna Pastore.

Correspondence and requests for materials should be addressed to A.P. (email: anna.pastore@opbg.net)
} 
a
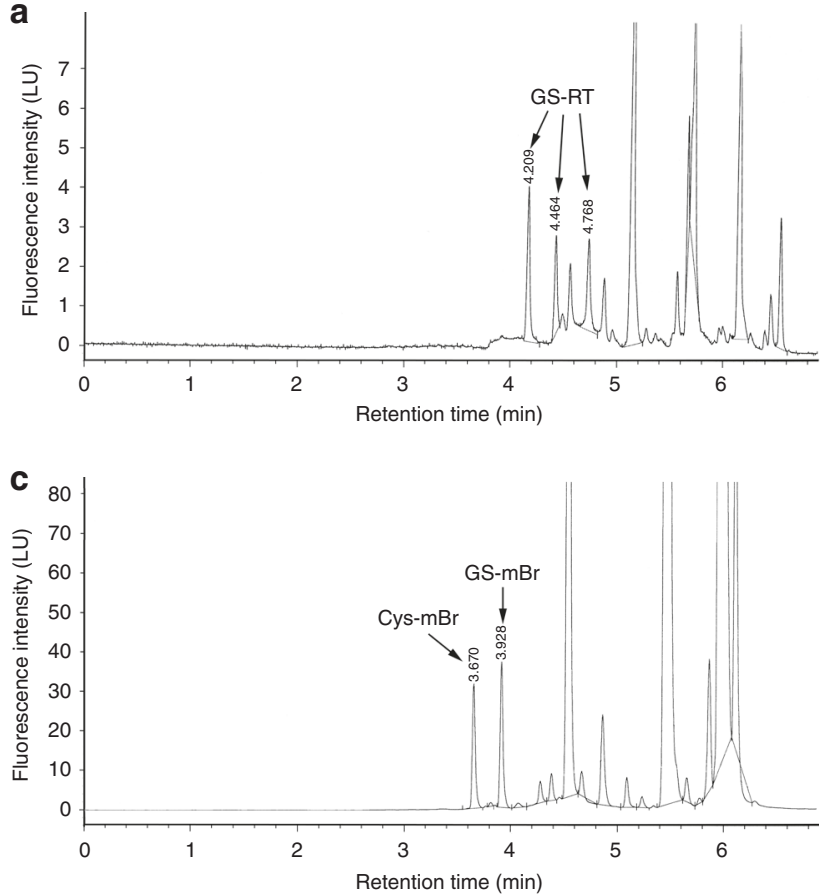

b
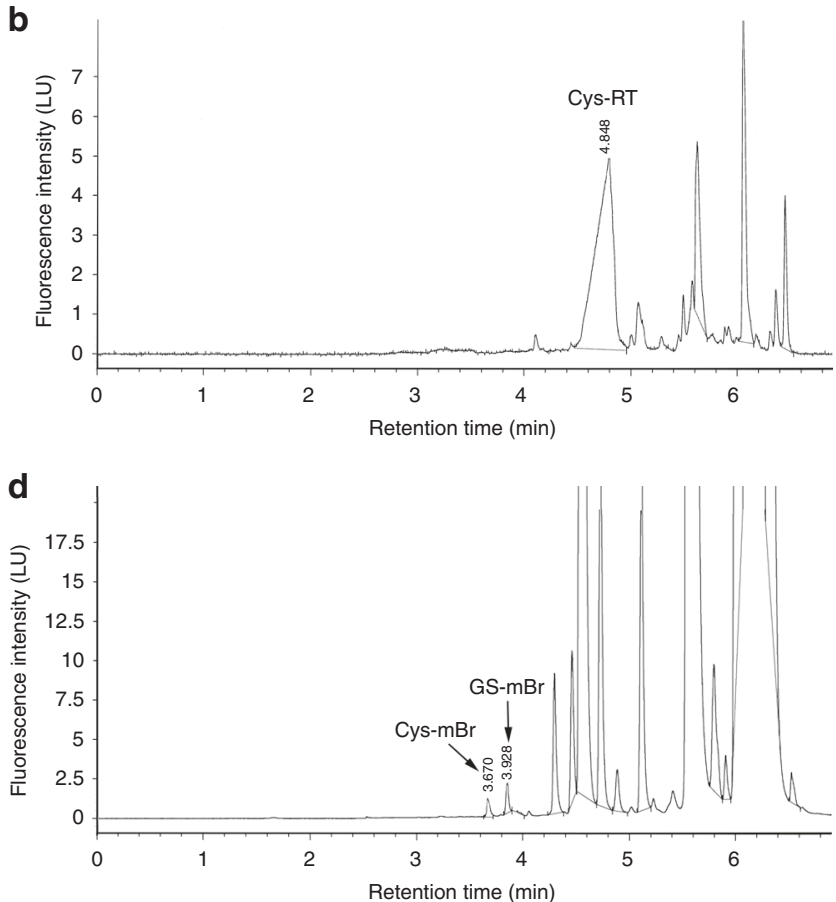

Fig. 1 RT probe reacts with both Cys and GSH in physiological conditions. a Reaction of $200 \mu \mathrm{M}$ of GSH with RT probe. In our experience, such concentrations of GSH are often found in various biological specimen, such as tissues or cells. GS-RT separation resulted in three almost symmetrical peaks at $4.209,4.464$, and 4.768 min of retention time, respectively. $\mathbf{b}$ Reaction of $200 \mu \mathrm{M}$ of Cys with RT probe. This Cys concentration is often found in various biological samples. The separation of Cys-RT resulted in one well-resolved symmetrical peak at 4.848 min retention time, with a response in terms of fluorescence intensity higher than those of GS-RT. c A representative chromatogram of thiols determination in mouse hippocampus cells. In these conditions, the levels of Cys (3.670 min retention time) and GSH (3.928 min retention time) are almost identical (110 and $125 \mu \mathrm{M}$, respectively). d Chromatogram of thiols determination in $\mathrm{H}_{2} \mathrm{O}_{2}$-treated HeLa cells. Levels of Cys and GSH are similar (20 and $28 \mu \mathrm{M}$, respectively)

\section{Methods}

Cell culture and treatment. HeLa cells were kindly provided by Lucio Miele, MD (Louisiana State University, Stanley S. Scott Cancer Center, New Orleans, LA, USA), and grown in RPMI medium, 10\% FBS, supplemented with $1 \%$ penicillin/ streptomycin and 1\% L-glutamine (All from Invitrogen, Carlsbad, CA, USA) in a humidified atmosphere of $5 \% \mathrm{CO}_{2} / 95 \%$ air. All the used aliquots were routinely tested for mycoplasma. HeLa cells were treated for $24 \mathrm{~h}$ with $100 \mu \mathrm{M} \mathrm{H}_{2} \mathrm{O}_{2}$ (Sigma, St Louis, MO, USA) in the culture medium and cell pellets were then collected and analyzed as reported below.

HPLC determination of Cys and GSH with RT probe derivatization. Reaction of standard solution of $200 \mu \mathrm{M}$ of Cys or GSH with RT probe was carried out following the manufacturer protocol (Kerafast, Boston, MA, USA). Overall, $10 \mu \mathrm{L}$ of the reaction mixture was injected into a $150 \times 4.6 \mathrm{~mm}$ Hypersil ${ }^{\text {tw }}$ ODS column (Thermo Fisher Scientific, Waltham, MA USA) equilibrated with $30 \mathrm{mmol} / \mathrm{L}$ ammonium nitrate and $40 \mathrm{mmol} / \mathrm{L}$ ammonium formate buffer, $\mathrm{pH} 3.6$ (buffer A). The thiols were eluted from the column with a 6 -min gradient of acetonitrile (buffer B) (0-4 min, 0-30\% buffer B; 4-5 min, 30-100\% buffer B; 5-6 min, $100 \%$ buffer B) at a flow rate of $1.5 \mathrm{~mL} / \mathrm{min}$ at ambient temperature. The HPLC was an Agilent 1290 (Agilent Technologies, Santa Clara, CA, USA), equipped with a fluorescence detector operating at excitation wavelengths of 405 and $488 \mathrm{~nm}$, and emission wavelength of $499 \mathrm{~nm}$.

HPLC determination of Cys and GSH with monobromobimane ( $\mathrm{mBr}$ ) derivatization. The cells were sonicated three times for $2 \mathrm{~s}$ in $100 \mu \mathrm{L}$ of $0.1 \mathrm{M}$ potassium phosphate buffer ( $\mathrm{pH}$ 7.2). After sonication, $50 \mu \mathrm{L}$ of $12 \%$ sulfosalicylic acid were added, and the Cys and GSH content in the acid-soluble fraction was determined (free Cys and free GSH). To measure cystine and oxidized glutathione (GSSG), cells were sonicated three times for $2 \mathrm{~s}$ in $0.1 \mathrm{~mL}$ of $0.1 \mathrm{M}$ potassium phosphate buffer (pH 7.2) containing $10 \mathrm{mM} \mathrm{N}$-ethylmaleimide. Cys and GSH levels were calculated by subtracting cystine and GSSG concentrations from free Cys and free GSH values. The derivatization procedure was performed as follows: $30 \mu \mathrm{L}$ of $4 \mathrm{~mol} / \mathrm{L}$ $\mathrm{NaBH}_{4}, 20 \mu \mathrm{L}$ of $2 \mathrm{mmol} / \mathrm{L}$ EDTA/DTT, $10 \mu \mathrm{L}$ of 1 -octanol and $20 \mu \mathrm{L}$ of $1.8 \mathrm{~mol} / \mathrm{L}$ $\mathrm{HCl}$ were placed in the derivatization vial containing $30 \mu \mathrm{L}$ of sample. After incubation for $3 \mathrm{~min}, 100 \mu \mathrm{L}$ of $1.5 \mathrm{~mol} / \mathrm{L} \mathrm{N}$-ethylmorpholine buffer, $\mathrm{pH} 8.0,400$ $\mu \mathrm{L}$ of distilled water, and $20 \mu \mathrm{L}$ of $25 \mathrm{mmol} / \mathrm{L}$ bromobimane were added. After additional 3-min incubation, $40 \mu \mathrm{L}$ of acetic acid was added, and $20 \mu \mathrm{L}$ of the reaction mixture was injected into a $150 \times 4.6 \mathrm{~mm}$ Hypersil ${ }^{\mathrm{m}}$ ODS column
(Thermo Fisher Scientific, Waltham, MA, USA) equilibrated with $30 \mathrm{mmol} / \mathrm{L}$ ammonium nitrate and $40 \mathrm{mmol} / \mathrm{L}$ ammonium formate buffer, $\mathrm{pH} 3.6$ (buffer A). The thiols were eluted from the column with a 6 -min gradient of acetonitrile (buffer B) (0-4 min, 0-30\% buffer B; 4-5 min, 30-100\% buffer B; 5-6 min, 100\% buffer B) at a flow rate of $1.5 \mathrm{~mL} / \mathrm{min}$ at ambient temperature. The HPLC was an Agilent 1290 (Agilent Technologies, Santa Clara, CA, USA), equipped with a fluorescence detector operating at excitation wavelengths of $390 \mathrm{~nm}$, and emission wavelength of $478 \mathrm{~nm}$.

Data availability. The data that support the findings of this study are available from the corresponding author upon reasonable request.

Received: 9 January 2018 Accepted: 29 March 2018

Published online: 23 April 2018

\section{References}

1. Mudd, S. H., Levy, H. L. \& Skovby, F. in The Metabolic and Molecular Bases of Inherited Disease 7th edn (eds Scriver, C. R., Beaudet, A. L., Sly, W. S., Valle, D.) 1229-1327 (McGraw-Hill, New York, 1995).

2. Pastore, A., Federici, G., Bertini, E. \& Piemonte, F. Analysis of glutathione: implication in redox and detoxification. Clin. Chim. Acta 1, 19-39 (2003).

3. Giustarini, D. et al. Assessment of glutathione/glutathione disulphide ratio and S-glutathionylated proteins in human blood, solid tissues, and cultured cells. Free Radic. Biol. Med. 112, 360-375 (2017).

4. Jiang, X. et al. Quantitative real-time imaging of glutathione. Nat. Commun. 8, 16087 (2017).

5. Pastore, A. et al. Fully automated assay for total homocysteine, cysteine, cysteinylglycine, glutathione, cysteamine, and 2-mercaptopropionylglycine in plasma and urine. Clin. Chem. 4, 825-832 (1998).

6. Guan, X., Hoffman, B., Dwivedi, C. \& Matthees, D. P. A simultaneous liquid chromatography/mass spectrometric assay of glutathione, cysteine, homocysteine and their disulfides in biological samples. J. Pharm. Biomed. Anal. 2, 251-261 (2003). 
7. Lee, S. G., Yim, J., Lim, Y. \& Kim, J. H. Validation of a liquid chromatography tandem mass spectrometry method to measure oxidized and reduced forms of glutathione in whole blood and verification in a mouse model as an indicator of oxidative stress. J. Chromatogr. B Anal. Technol. Biomed. Life. Sci. 1019, 45-50 (2016).

8. Yin, C. X., Xiong, K. M., Huo, F. J., Salamanca, J. C. \& Strongin, R. M. Fluorescent probes with multiple binding sites for the discrimination of Cys, Hcy, and GSH. Angew Chem. Int. Ed. Engl. 43, 13188-13198 (2017).

9. Spence, M. T. \& Johnson, I. D. The Molecular Probes Handbook: A Guide to Fluorescent Probes and Labelling Technologies. Chapter 2: Thiol-Reactive Probes 11th edn (Live Technologies Corporation, Carlsbad, 2010).

10. Lu, S. C. Glutathione synthesis. Biochim. Biophys. Acta 5, 3143-3153 (2013).

11. Pastore, A. et al. Actin glutathionylation increases in fibroblasts of patients with Friedreich's ataxia: a potential role in the pathogenesis of the disease. $J$. Biol. Chem. 43, 42588-42595 (2003).

12. Pastore, A. et al. Glutathione: a redox signature in monitoring EPI-743 therapy in children with mitochondrial encephalomyopathies. Mol. Genet. Metab. 2, 208-214 (2013).

13. Pastore, A. et al. Glutathione metabolism in cobalamin deficiency type C (cblC). J. Inherit. Metab. Dis. 1, 125-129 (2014).

14. Elmonem, M. A. et al. Cystinosis (ctns) zebrafish mutant shows pronephric glomerular and tubular dysfunction. Sci. Rep. 7, 42583 (2017).

15. Pauletti, A. et al. Targeting oxidative stress improves disease outcomes in a rat model of acquired epilepsy. Brain 7, 1885-1899 (2017).

\section{Acknowledgements}

This work was supported in part by the Associazione Italiana per la Ricerca sul Cancro (AIRC) (IG 15312 to R.R.).

\section{Author contributions}

C.C. and G.D.G. performed experiments; R.R. and A.P. designed experiments, performed data analysis, and wrote the manuscript.

\section{Additional information}

Competing interests: The authors declare no competing interests.

Reprints and permission information is available online at http://npg.nature.com/ reprintsandpermissions/

Publisher's note: Springer Nature remains neutral with regard to jurisdictional claims in published maps and institutional affiliations.

\begin{abstract}
(c) (i)
Open Access This article is licensed under a Creative Commons Attribution 4.0 International License, which permits use, sharing, adaptation, distribution and reproduction in any medium or format, as long as you give appropriate credit to the original author(s) and the source, provide a link to the Creative Commons license, and indicate if changes were made. The images or other third party material in this article are included in the article's Creative Commons license, unless indicated otherwise in a credit line to the material. If material is not included in the article's Creative Commons license and your intended use is not permitted by statutory regulation or exceeds the permitted use, you will need to obtain permission directly from the copyright holder. To view a copy of this license, visit http://creativecommons.org/ licenses/by/4.0/.
\end{abstract}

(C) The Author(s) 2018 